\title{
Incidencia de hepatitis $B$ en el servicio de ginecología y obstetricia del Hospital Militar Central
}

\author{
Dres. Jairo de la Cruz S.*, Jaime Orejarena S.**, Vicente Carmona P.**
}

RESUMEN. Se analizaron mediante la técnica de ELISA 224 muestras de sangre tomadas a pacientes que concurrieron a consulta en el servicio de obstetricia y ginecología del Hospital Militar Central con el fin de establecer la incidencia de positividad para antígeno de superficie de la hepatitis B. Se establecieron dos grupos que incluian pacientes con factores de riesgo y sin ellos; en el total de las muestras analizadas siete pacientes presentaron el título positivo ( $3.6 \%)$, tres de ellas no acusaron factores de riesgo, dos pertenecían al grupo de personal de salud, una había sido transfundida y una era drogadicta.

La finalidad al establecer la incidencia de títulos positivos es ofrecer a los recién nacidos de estas madres, la oportunidad de recibir una inmunoprofilaxis pasiva y activa con el objeto de prevenir la adquisición de la enfermedad.

PALABRAS CLAVES: Embarazo, hepatitis B, antígeno de superficie de la hepatitis B.

SUMMARY. Signs of blood were analized by means of ELISA 224 technique. They were taken from patients that attended consultation at the obstetrice and gynecology service at the Military Central Hospital in order to establish the incidence of positivity for the hepatitis B surface antigen. It was established two groups: patients with risk factors and patient without them. Seven patients of the total analyzed signs presented positive title (3.6\%), three of them didn't accused risk factors, two belong to the health personal group, one person had been transfused and one was drug addict.

The purpose to establish the incidence of positive titles is to offer to the just born of these mothers the opportunity of receiving an inmune-prophylaxis pasive and active in order to prevent acquisition of the illness.

KEYWORDS: Pregnancy, hepatitis B, hepatitis B surface antigen.

\section{Introducción}

En los últimos años se ha informado a nivel mundial de un gran número de casos de hepatitis $\mathrm{B}$ aguda durante el primer año de vida, de los cuales algunos evolucionan en la edad adulta como hepatitis crónica sintomática o asintomática; más o menos el $25 \%$ de estos casos mueren con cirrosis o hepatoma en plena edad productiva ( 3 a y 4 a década de la vida), lo cual implica un grave problema social $(4,12$, 29, 31).

Si tenemos en cuenta que esta enfermedad puede ser prevenible, cuando la transmisión es vertical, hasta en un $95 \%$ $(6,9,18,26)$, es importante llevar a cabo exámenes que nos sirvan de tamizaje a un bajo costo, como lo es el antígeno de superficie de la hepatitis B (HBsAg), y de esta forma incluirlo dentro de los exámenes solicitados a toda paciente en el control prenatal.

Desconocemos en nuestro hospital la incidencia y prevalencia de la hepatitis B, de allí la necesidad de realizar este estudio con el objetivo de investigar su incidencia en las pacientes usuarias del servicio de ginecología y obstetricia

\footnotetext{
* Profesor Asociado.

** Residentes Universidad Militar Nueva Granada, Escuela Militar de Medicina y Ciencias de la Salud, Hospital Militar Central; Sección Ginecología y Obstetricia.
}

del Hospital Militar Central e identificar la relación entre los títulos positivos para HBsAg y los factores de riesgo para adquirir la enfermedad, y de esta manera, ofrecer un manejo adecuado durante el período neonatal a aquellas cuyo título sea positivo. Se conoce, por estudio parcial realizado en nuestro país, que la incidencia es del $8,5 \%$ de positividad para el HBsAg (25).

\section{Recuento histórico}

El origen viral de la hepatitis A se descubre en la década del 40 y en 1965 se comenta sobre el de la hepatitis B, cuando Blumberg y asociados comunican el "nuevo" antígeno de superficie sérico de Australia (22). Posteriormente se han revelado nuevas pruebas serológicas para estudio y análisis de la hepatitis B contando en el momento con pruebas de radioinmunoensayo para los tres tipos de antígenos $\mathrm{y}$ anticuerpos.

Aproximadamente en 1973 se empezaron a encontrar neonatos infectados con virus de la hepatitis B, de los cuales, unos eran asintomáticos y otros presentaron hepatitis leve, severa o mortal $(9,11,19,24)$. Esto dio origen a estudios con el objeto de buscar la relación existente entre las mujeres embarazadas, portadoras crónicas, y la infección perinatal, la que puede llegar a oscilar entre el 40 y el $60 \%$ para algunos autores $(19,22,26,29)$, o entre el 70 y el $90 \%$ para otros $(8,16,29)$. 


\section{Virus de la hepatitis}

El virus de la hepatitis A es un virus RNA, de $27 \mathrm{~nm}$ de la familia de los Picorna hepadna virus, mientras que el virus de la hepatitis B es DNA de $42 \mathrm{~nm}$ de la familia de los Hepadna, que contiene una partícula "DANE". La hepatitis No A No B o C se difunde, generalmente, por el uso de transfusiones sanguíneas o drogas parenterales. El virus de la hepatitis $\mathrm{C}$ parece ser DNA y su diagnóstico se puede hacer por la detección del Ac viral C, el cual consiste en un polipéptido recambiante con clonos de cepas virus hepatitis C, usada para la detección de anticuerpos virales circulantes, descrito en $1988(5,15,17,23)$.

Recientemente ha sido identificada la hepatitis Delta o virus de la hepatitis $\mathrm{D}$, siendo una replicación del virus de la hepatitis B, y debe ocurrir en una co-infección o superinfección de hepatitis $B(1,22,25)$.

\section{Antígenos y anticuerpos de la hepatitis B}

El sistema de marcadores de la hepatitis B aparenta ser de difícil interpretación, pero se ha simplificado y consta de tres antígenos y sus respectivos anticuerpos, teniendo importancia cada uno en el pronóstico y diagnóstico de la infección aguda o crónica (Tabla 1).

El virus de la hepatitis B (HBV) mide $42 \mathrm{~nm}$ y tiene una imagen similar a un "buñuelo enroscado" que contiene en el centro la partícula Core con su antígeno C, el DNA, el antígeno E y el fragmento de DNA- polimerasa (DNAp). El DNAp es una pequeña partícula específica de $20 \mathrm{~nm}$, perteneciente a un DNA incompleto, el cual no es infeccioso pero indica una posible infección en período de incubación.

La partícula Core está rodeada por el antígeno de superficie y todo constituye la partícula DANE (Figura 1) $(7,10$, 14, 22).

$\mathrm{El}$ antígeno de superficie (HBsAg) es el primer marcader en elevarse cuando hay una infección aguda. Se puede presentar en varias formas morfológicas en el suero, estas formas tienen en común la partícula "a" a la cual se adiciona una de las otras cuatro partículas: "d", " $y$ ", "w", o "r", para conformar así los cuatro subtipos de HBsAg: "adw", "adr",

Tabla 1

MARCADORES SEROLOGICOS DE LA HEPATITIS B

\begin{tabular}{lll}
\hline MARCADOR & ABREVIACION & \multicolumn{1}{c}{ COMENTARIOS } \\
\hline $\begin{array}{l}\text { Ag SUPERFICIE } \\
\text { HEPATITIS }\end{array}$ & HBsAg & $\begin{array}{l}\text { Llamado “Ag Australia" " *Ag asociado a Hepatitis" } \\
\text { Identificado en suero 30-60 días después de la } \\
\text { exposición a HBV. }\end{array}$ \\
Ag e HEPATITIS B & HBeAg & $\begin{array}{l}\text { Correlacionado con títulos altos virales en suero } \\
\text { e infectividad del suero. }\end{array}$ \\
$\begin{array}{l}\text { Ag CORE HEPATITIS } \\
\text { B HBcAg }\end{array}$ & $\begin{array}{l}\text { No detectable en suero. } \\
\text { Desarrollado después de resolverse la infección. }\end{array}$ \\
Ac a HBsAg & Anti HBS & $\begin{array}{l}\text { Indica inmunidad HBV después de la infección; res- } \\
\text { ponsable de la vacuna HBV, o Ac pasivo del HBIg. }\end{array}$ \\
Ac a HBeAg & Anti HBe & $\begin{array}{l}\text { Si hay HBs Ag positivo en suero y Anti HBe es } \\
\text { de poca infectividad. }\end{array}$ \\
Ac a HBcAg & Anti HBc & Marca que el paciente tuvo o tiene la infección. \\
IgM Ac A HBcAg & Anti HBc IgM & $\begin{array}{l}\text { Primero en aumentar en infección aguda HBV. } \\
\text { Persiste 4-6 meses. Sirve como marcador } \\
\text { de infección reciente. }\end{array}$ \\
\hline
\end{tabular}

Figura 1

VIRUS DE LA HEPATITIS B

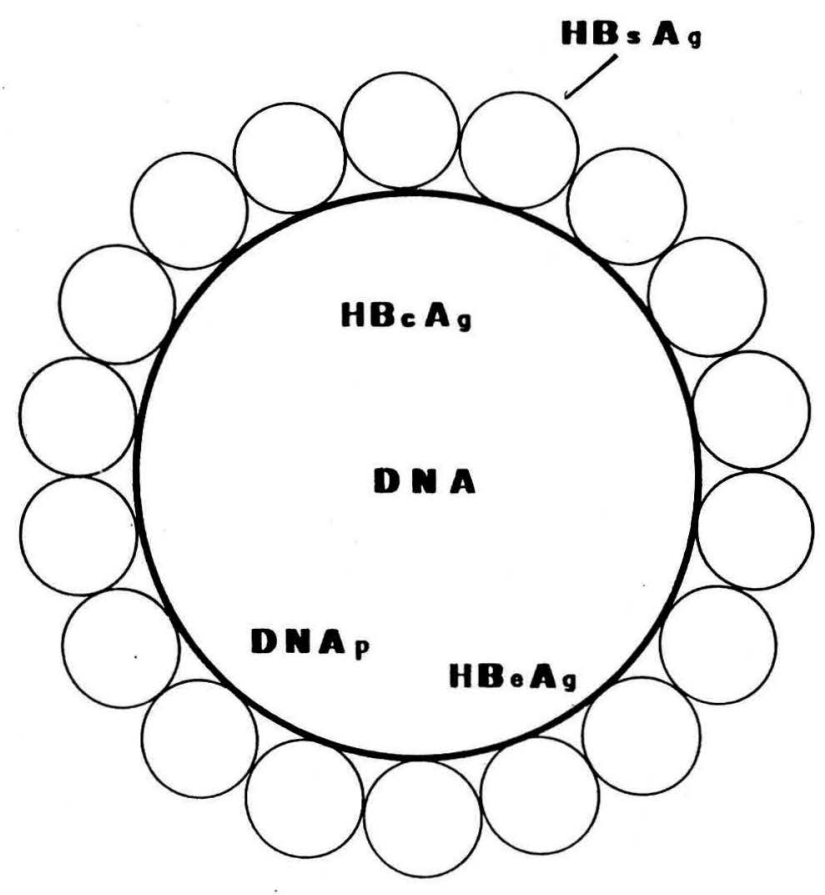

"ayw" y "ayr" que vienen siendo los subtipos prevalentes para las diferentes regiones geográficas marcando las diferencias epidemiológicas $(22,33)$.

$\mathrm{El}$ antígeno $\mathrm{E}(\mathrm{HBeAg})$ es una proteína soluble considerada como parte integral de la partícula Core HVB y sólo es detectado si el HBsAg es positivo, correlacionándose con la infectabilidad del suero y el número de partículas infectantes. Hay dos subtipos de los cuales el 1 es más común que el 2 en sueros con HBsAg positivos; pero el 2 se correlaciona con infección crónica.

$\mathrm{El}$ antígeno Core $(\mathrm{HBcAg})$ no es detectable en el suero pero se puede detectar en el núcleo de los hepatocitos infectados.

Los anticuerpos contra los diferentes tipos de antígenos se desarrollan posterior a la elevación de éstos e indican inmunidad después de la infección.

$\mathrm{El}$ anticuerpo IgM al HBcAg (Anti HBcIgM) es el primero en aumentar en una infección aguda, persiste de cuatro a seis meses, sirve como marcador para una infección reciente, para controlar la infección aguda, o la reinfección de una crónica (22).

\section{Prevalencia de marcadores de infección de hepatitis B}

El riesgo de adquirir la infección por hepatitis $\mathrm{B}$ en el primer año de vida, es muy variado en las diferentes poblaciones. En los Estados Unidos este riesgo llega al 5\%, en Asia varía del 5 al $15 \%(1,22)$. La prevalencia del $\mathrm{HBsAg}$ oscila según los diferentes estudioß y regiones entre el $0.1 \%$ al $24 \%(1,8,19,21,22)$. 


\section{Cuadros clínicos de la hepatitis B}

\section{A) HEPATITIS B AGUDA CON RESOLUCION}

La clínica se inicia entre las seis semanas y los seis meses de exposición al virus, manifestándose principalmente por ictericia entre el segundo y el tercer mes, con elevación de las transaminasas entre el primero y el cuarto mes. $\mathrm{El} \mathrm{HBsAg}$ se empieza a elevar después de la semana de exposición, con elevación del $\mathrm{HBeAg}$ después de la tercera semana; estos títulos empiezan a disminuir hacia el tercero o cuarto mes y el anti HBs se empieza a presentar hacia el quinto mes, persistiendo durante toda la vida, formándose un período de ventana de aproximadamente cuatro semanas. El período de ventana es el lapso comprendido entre la ausencia de HBsAg y el inicio de los anticuerpos correspondientes (Figura 2) $(18,22)$.

Figura 2

HEPATITIS B AGUDA CON RESOLUCION

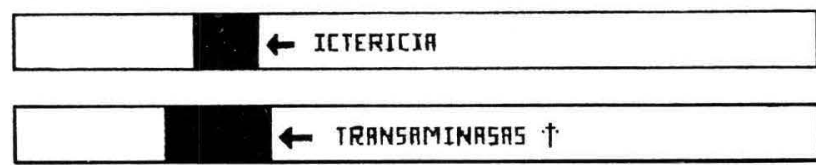

HEs胿 $\square$
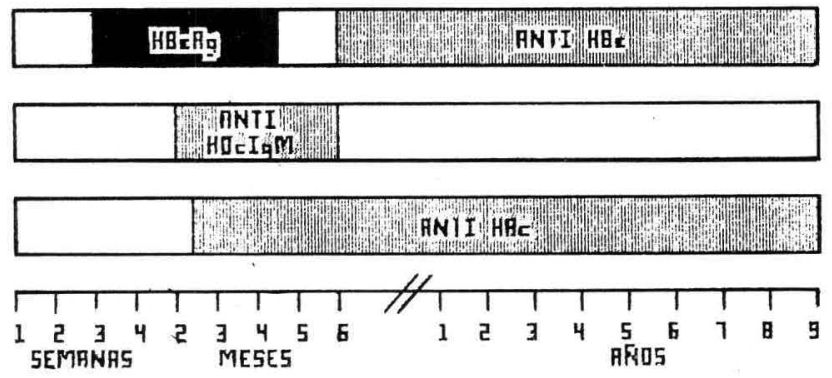

Figura 3

INFECCION POR HEPATITIS B CRONICA ACTIVA

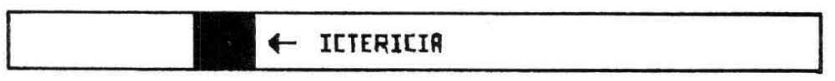

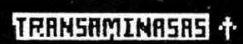

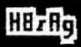

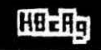
FNTI He:

\begin{tabular}{|l|l|}
\hline ANTI HePTipm & \\
\hline
\end{tabular}
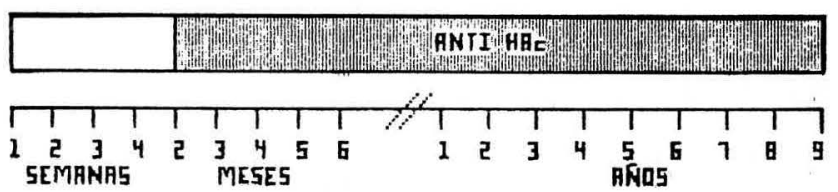

Figura 4

INFECCION POR HEPATITIS B CRONICA ASINTOMATICA

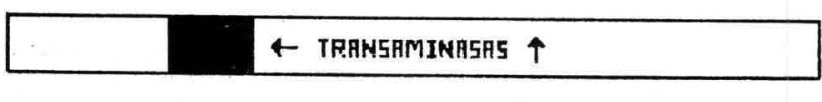

\section{H明鸠}

\section{Haling}

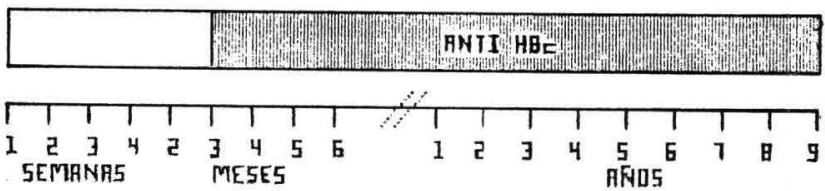

B) INFECCION POR HEPATITIS B CRONICA ACTIVA Este cuadro clínico se inicia como el de la hepatitis B aguda, presentando las siguientes variantes: 1) elevación persistente de las transaminasas; 2) títulos constantemente altos de HBsAg por el resto de la vida; 3 ) títulos de $\mathrm{HBeAg}$ aumentados hasta tres o cuatro años después de la exposición al virus, con títulos de anti $\mathrm{HBe}$ presentes después del cuarto o quinto año.

El anti HBcIgM y el anti HBcIgG no muestran cambio al respecto al cuadro de la aguda (Figura 3) $(18,22)$. C) INFECCION POR HEPATITIS B CRONICA PERSISTENTE ASINTOMATICA

Por lo general este cuadro no se acompaña de ictericia. La elevación de las transaminasas dura de dos a cuatro meses. Los títulos de HBsAg persisten altos por toda la vida y los de $\mathrm{HBeAg}$ se aumentan por seis meses, iniciando los títulos de anti HBe al final del primer año. La anti HBcIgM no se presenta y los títulos de anti $\mathrm{HBc}$ aparecen a partir del segundo mes persistiendo durante toda la vida (Figura 4) $(18,22)$.

\section{Transmisión perinatal de la hepatitis B}

La hepatitis B se transmite principalmente por tres mecanismos: 1) por vía percutánea, por sangre o productos derivados de ésta; 2) contacto sexual; 3) transmisión perinatal. Se estima el número de personas en el mundo infectadas crónicamente con el HVB en un 5\% (más o menos doscientos millones de personas) (25). Además, el HVB es considerado, por muchos, el segundo agente carcinogénico, después del cigarrillo. Por consiguiente, es necesario tratar de detener la propagación de esta infección.

El HVB se encuentra presente en casi todas las secreciones del cuerpo como son las lágrimas, la saliva, el semen, los exudados cutáneos, la leche y la orina, entre otros, lo que hace a las transmisiones percutánea y perinatal las más comunes. Del $40 \%$ al $60 \%$ de los infantes desarrollan hepatitis B cuando la madre presenta la enfermedad en el tercer trimestre del embarazo; esta transmisión se hace posiblemente durante el parto y el período neonatal, fundamentándose esta posibilidad por las siguientes razones: 1) el HVB es un virus DNA grande que pasa difícilmente la barrera placentaria; 2) los infantes, por lo general, son seronegativos al nacimiento y los marcadores se hacen positivos hacia el 
segundo o cuarto mes, después del período de incubación; 3) el $95 \%$ de las pacientes HBsAg positivas en suero tienen HBsAg positivo en secreción vaginal, contra un $33 \%$ de positividad en líquido amniótico (14, 20, 22, 26, 30). Por lo general la infección aguda en neonatos es asintomática con un riesgo de conversión hacia portador crónico del $90 \%$, teniendo una posibilidad del $25 \%$ de morir por cirrosis o hepatocarcinoma en la tercera o cuarta década de la vida (edad productiva) originando un grave problema social y económico para la familia y el país $(4,8,12,16,25,29,31)$.

\section{Interpretación del perfil serológico}

La interpretación de los diferentes marcadores serológicos del HVB se hace con base en la presencia o no de HBsAg, $\mathrm{HBeAg}$ o $\mathrm{HBe}$ y el anti $\mathrm{HBcIgM}$, de la siguiente manera: 1) $\mathrm{HBsAg}$ positivo con $\mathrm{HBeAg}$ positivo: la paciente presenta la enfermedad y tiene alto poder infeccioso, por vía percutánea o perinatal, del 70 al $90 \%$. Si presenta títulos de HBcIgM la infección lleva menos de seis meses o hay reinfección. Si no los hay la paciente presenta una infección crónica $(22,27)$.

2) HBsAg positivos con anti $\mathrm{HBe}$ positivos: la paciente es portadora crónica, pero el poder de infectividad es bajo, 10 al $20 \%(22,27)$.

3) Si la paciente no presenta títulos de $\mathrm{HBsAg}$ se puede considerar que no ha presentado la enfermedad en forma aguda o crónica.

\section{Tratamiento de la infección perinatal}

El tratamiento se debe administrar a todo recién nacido, hijo de aquella mujer seropositiva de $\mathrm{HBsAg}$, durante el tercer trimestre. La combinación de inmunoprofilaxis pasiva y activa posee un $85-95 \%$ de efectividad para prevenir la adquisición de la enfermedad durante el primer año de vida $(22,26)$.

Los recién nacidos se deben inmunizar después del parto, ya sea por vía vaginal o por cesárea, de la siguiente forma: Administrar $0.5 \mathrm{cc}$ de gama-globulina hiperinmune para la hepatitis B (HBIG) intramuscular, idealmente en las primeras doce horas de vida, con un máximo de 48 horas. Además, se debe administrar vacuna para la hepatitis B a dosis de $10 \mathrm{ug}$ o $0.5 \mathrm{ml}$ (la mitad de la dosis del adulto) por vía intramuscular, aplicándola al momento de nacer, al mes y a los seis meses de vida, a igual dosis, con control de HBsAg y anti HBs a los nueve meses de edad $(22,26)$.

\section{Metodología}

Se solicitó el estudio de HBsAg a todas aquellas pacientes que asistieron a la consulta de control prenatal, en el Hospital Militar Central, desde el primero de septiembre de 1988. Estas pacientes se remitían al Laboratorio del Banco de Sangre de la misma institución, donde les tomaban muestra en sangre venosa, la cual se procesaba mediante la técnica de inmunoensayo enzimático, Elisa, consistente en la incubación periódica en esferas cubiertas de anticuerpo de $\mathrm{HBsAg}$ (cobayo) a temperaturas de $38-41^{\circ} \mathrm{C}$ durante un tiempo cambiante de dos, una y media horas, respectivamente. Posteriormente era leído por personal técnico del laboratorio, tomando como dato reactivo los que estaban por encima del valor crítico del $10 \%$, se repetía el proceso para los resultados reactivos. El test de Elisa es tan sensible que detecta niveles de HBsAg superiores a 2,5 nanogramos/ml (21).

A todas las pacientes se les documentaba: número de historia, edad, edad gestacional, riesgo para la adquisición de la enfermedad. Estos factores de riesgo son los con scidos tradicionalmente:

1. Personal médico o paramédico (enfermeras, jefes, auxiliares, odontólogas, bacteriólogas).

2. Pacientes que trabajen en guarderías o instituciones de educación especial.

3. Antecedentes transfusionales.

4. Drogadicción.

5. Antecedente de hepatitis o hepatopatía crónica de origen no determinado.

6. Antecedente de enfermedades venéreas en más de una ocasión.

7. Esposo portador de HBsAg.

A las pacientes con resultado "reactivo" se les advirtió el riesgo y se les identificó con documento especial, anotando en él la información pertinente, para ser presentado en el momento del parto y de esta manera informar al servicio de neonatología y pediatría infecciosa para llevar a cabo la inmunoprofilaxis, como se relató anteriormente; además, se les practicó, posteriormente, $\mathrm{HBeAg}$ y anti $\mathrm{HBc}$ con miras a determinar el estado clínico de la enfermedad.

\section{Resultados}

Se analizaron muestras de 224 pacientes, de las cuales 194 estaban en control prenatal, 29 en primer trimestre y 165 en el segundo y tercer trimestre; 30 pacientes acudían a consulta preconcepcional. Gráfica 1 .

Entre las 194 pacientes de control prenatal se encontraron 7 con HBsAg positivo, equivalente al 3.6\%. Gráfica 2 .

La distribución por factor de riesgo fue la siguiente: 3 pacientes $(42.9 \%)$ no tenían factor de riesgo. Dos $(28.6 \%)$ trabajaban en salud, una $(14.3 \%)$ se había transfundido y una (14.3\%) tenía antecedente de drogadicción. Gráfica 3.

Del grupo de 224 pacientes 66 de ellas tenían algún factor de riesgo y $158(70.5 \%)$ no lo presentaban. Los factores de

\section{Gráfica 1 HEPATITIS B DISTRIBUCION POR EDAD GESTACIONAL}

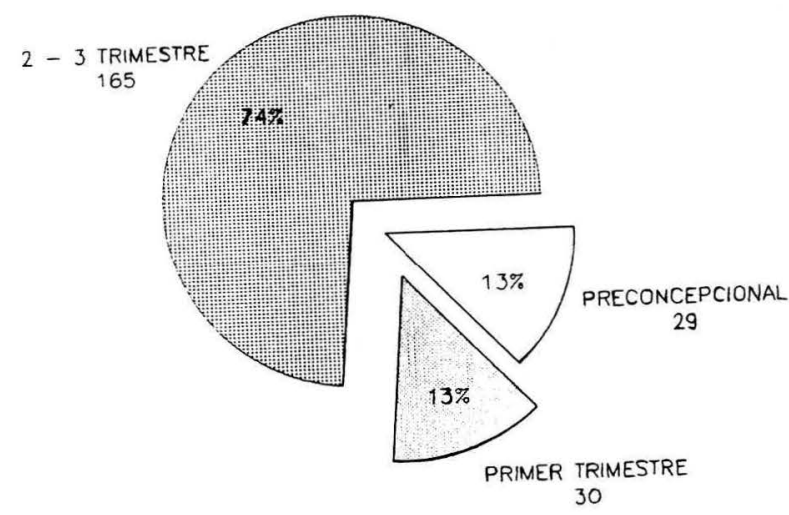


Gráfica 2

HEPATITIS B

INCIDENCIA EN PACIENTES EMBARAZADAS

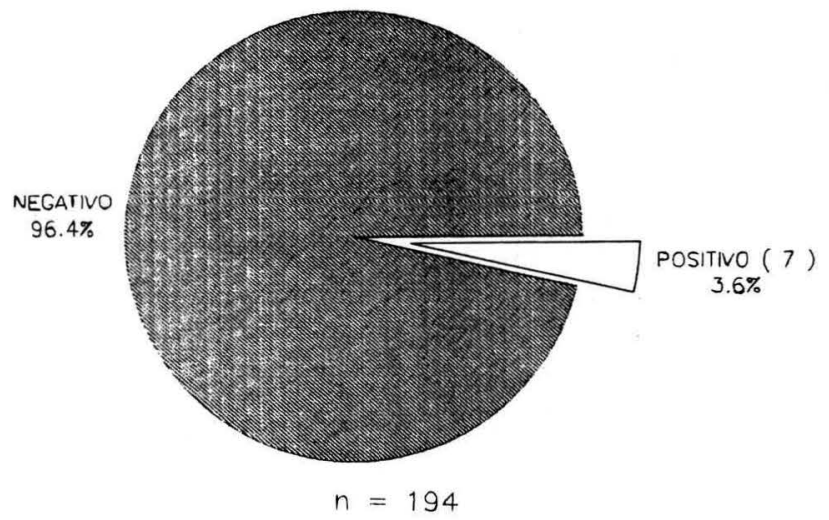

Gráfica 3

HEPAIITIS B

FACTORES DE RIESGO EN HBSAg POSITIVO

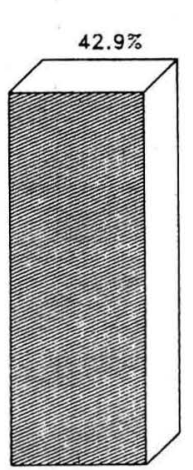

SIN RIESGO

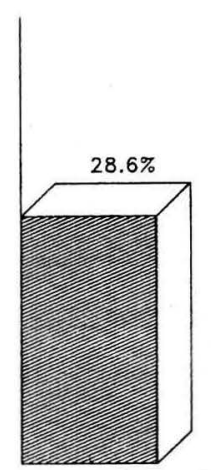

PERS SALUD

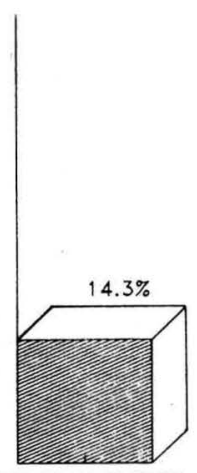

ANT TRANSFUSION

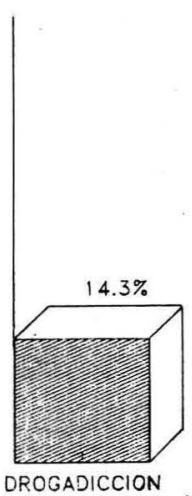

DROGADICCION riesgo se repartieron así: personal de la salud fueron 43 pacientes para un 19,2\%; pacientes con antecedente de enfermedad venérea fueron 14 para un $6.3 \%$; seis pacientes se habían transfundido $(2.7 \%)$; dos pacientes $(0.9 \%)$ tenían antecedente de drogadicción y una paciente $(0.45 \%)$ había padecido una hepatopatía. Gráfica 4.

La correlación entre los factores de riesgo y la positividad de la HBsAg, fue como sigue: de 43 pacientes del personal de salud, 2 presentaron títulos positivos o sea un $4.7 \%$. De las 6 mujeres con transfusiones una (1) era positiva (16.7\%); y de las 158 sin factor de riesgo tres (3) fueron positivas (1.9\%). Gráfica 5.

De las siete pacientes con $\mathrm{HBsAg}$ positivo a seis les fue practicado $\mathrm{HBeAg}$ y anti $\mathrm{HBc}$ y sólo dos resultaron positivas, de ellas, una presentó positividad en las muestras de cordón y en el control del recién nacido al mes; a los 6 meses las pruebas se negativizaron; este caso se presentó en paciente con antecedente transfusional, con múltiples cerclajes cervicales en embarazos previos.

De los siete (7) recién nacidos de madres con título positivo, a uno (1) no se le pudo hacer seguimiento, pues los resultados se obtuvieron después del parto y la paciente no residía en Bogotá; otro caso tenía 33 semanas de gestación en el momento de cerrar el estudio; de las cinco (5) restantes sólo una (1) tuvo pruebas positivas en el cordón y los cinco (5) fueron negativos a los seis meses de control.

\section{Discusión}

La incidencia de positividad del HBsAg en pacientes embarazadas, usuarias del Hospital Militar Central, es del $3.68 \%$.

De los factores de riesgo el que más se correlaciona con la positividad del HBsAg es el antecedente de drogadicción $(50 \%)$, seguido de antecedente transfusional con un $16.7 \%$ y de personal de salud con un $4.7 \%$.

En el grupo de pacientes sin riesgo se presentó positividad en la prueba en 3 pacientes (1.9\%), lo que nos indica la utilidad de practicar la prueba a toda paciente embarazada.

Aunque es bajo en número de recién nacidos productos de madres con HBsAg positivo, en todos se obtuvo negatividad en las pruebas, a los seis meses, pudiéndose decir que la profilaxis es efectiva.

Se debe solicitar a toda mujer embarazada el título de HBsAg en el tercer trimestre de su gestación.

Si partimos de la base que en el Hospital Militar Central se atienden anualmente 1.460 partos, en promedio, y tene-

\section{Gráfica 4 \\ HEPATITIS B \\ DISTRIBUCION SEGUN FACTYORES DE RIESGO}

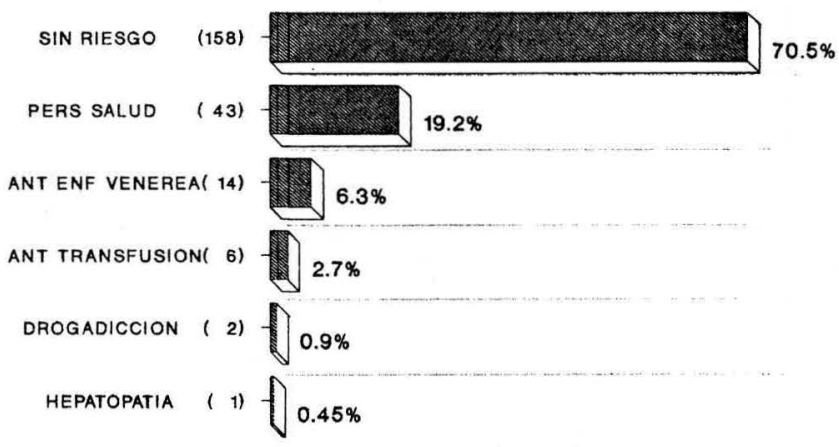

Gráfica 5

HEPATITIS B

CORRELACION DE RIESGO CON HBSAg POSITIVO

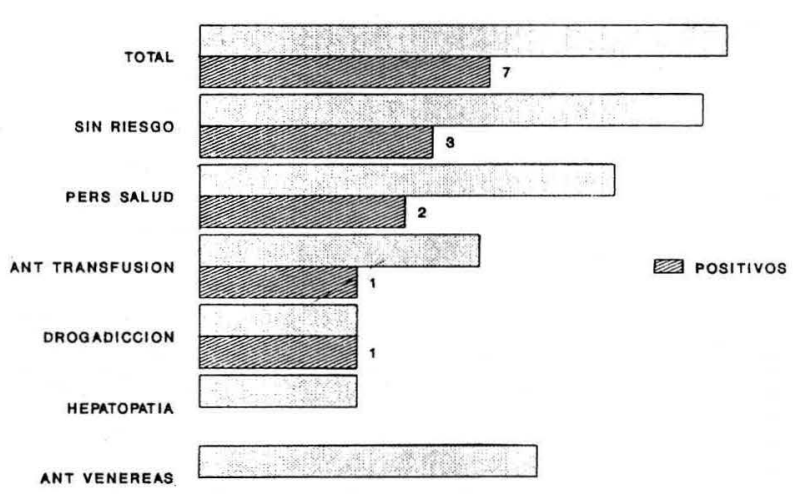


mos una incidencia de $3.68 \%$, obtendríamos un total de 53 pacientes embarazadas con $\mathrm{HBsAg}$ positivo, con igual número de recién nacidos, los cuales podrían recibir el tratamiento profiláctico de la enfermedad, evitando de esa manera que en 40 ó 50 años tuviéramos un total de 14 pacientes, aproximadamente, con enfermedad hepática, tipo cirrosis o carcinoma hepatocelular, con todos los problemas de orden social que esto acarrearía.
Si extendemos esta incidencia a nivel nacional las cifras serían aún más impresionantes.

De tal manera, con sólo obtener títulos de HBsAg en el grupo de mujeres embarazadas y realizando la profilaxis adecuada en aquellas positivas, sería suficiente para poder manifestar que se está haciendo algo en beneficio de la salud de nuestros compatriotas.

\section{BIBLIOGRAFIA}

1. Advisary Committee on Inmunization Practice: Recomendation for protection against viral hepatitis. MMWR 1985; 34: 313 .

2. AREVALO, J.A.; WASHINGTON, A.E. Cost-effectiveness of perınatal screening and inmunization for hepatitis B virus. JAMA 1988; 259: 365-369.

3. BEASLEY et al. Efficay of hepatitis B immune globulin for prevention of perinatal transmission of the hepatitis B virus carrier state. Hepatology 1983; 3: 135-41.

4. BEASLEY, R.P.; HWANG, L.Y.; LEE, G.C.Y. et al. Prevention of perinatally transmitted hepatitis $B$ virus infections with hepatitis B immune globulin and hepatitis B vaccine. Lancet 1983; 2: 1099-102.

5. BRUIX, J.; CALVET, X.; COSTA, J. et al. Prevalence of antibodies to hepatitis C virus in Spanish patients with hepatocellular carcinoma and hepatic cirrhosis. Lancet 1985; 28: 1004-1008.

6. Committee on Infectous diseases: Prevention of hepatitis B virus infections. Pediatrics 1985; 75: 362.

7. CZAJQ, A.J. Serologic markers of hepatitis A and B in acute and chronic liver disease. Mayo Clin Proc 1979; 54: 721.

8. CRUZ, FRENTZEN. Hepatitis B: A case for prenatal screening of all patients. Am J Obste Gyneco 1987; 156: 1180-3.

9. DELAPLANE, D.; YOGEV, R.; CRUSSI, F.; SHULMAN, S.T Fatal hepatitis B in early infancy: the importance of identifying HBsAg-positive pregnant women and providing immunoprophylaxis to their newborns. Pediatrics 1983; 72: 176-80.

10. DREESMAN, G.R.; HOLLINGER, F.B.; MELNICK, J.I. Biophysical and biochemical properties of purified preparations of hepatitis B surface antigen. (HBsAg). Am J Med Sc 1975; 270: 123.

11. FAWAZ. Repetitive Maternal-Fetal transmition of fetal hepatitis B. $\mathbf{N}$ Engl J Med 1975; 293: 1357-9.

12. Hepatocellular carcinoma and hepatitis B virus markers in Europe and U.S.A. (letter). Lancet 1979; Feb. 24.

13. HOOFNAGLE, J.H. Perinatal hepatitis B virus infection; screening of pregnant women and protection of the infant. Ann Inter Med 1987; 107(3): 412-13.

14. HOLLINGER, F.B. Serologic evaluation of viral hepatitis. Hosp Pract 1987; 22: 101

15. Hepatitis C. Idaliba 1989; Agost 11.

16. KANE. Routine prenatal screening for hepatitis B surface antigen. JAMA $1988 ; 259(3)$.

17. KUO, G.; CHOO, Q.L. et al. An assay for circulating antibodies to a major etiologic virus of human non-A, non-B hepatitis. Science 1989; 244: $362-364$.
18. KRUGMAN, S. Viral hepatitis: 1985 Update. Pedriatr Rev 1985; 7: 3

19. KUMAR; DAESON; NEAL. Should all pregnant women be screening for hepatitis B. Ann Inter Med 1987; 117: 273-77.

20. LEE, AKY; IP, H.M.H.; WONG, V.C.W. Mechanisms of maternal-fetal transmision of hepatitis B virus. J Infect Dis 1978; 138: 668.

21. MAUREEN et al. Failure of centers for disease control criteria to identify hepatitis B infection in a large municipal obstetrical polulation. Ann Inter Med 1987; 107: 335- 37.

22. MORVEN, S.E. Hepatitis B serology. Help in interpretation. Clin Pediatr of North America 1988; 35(3): 503-15.

23. QUI-LIM CHOO; G. KUO et al. Isolation of a cDNA clone derived from a bloos-borne non-A, non-B viral hepatitis genome. Science 1989; 244: 359-362.

24. SCHWEITZER, I.L. Viral hepatitis B in neonates and infant. Am J Med 1973; 55: 762-71.

25. SIERRA, F.; GOMEZ, R.O.; BOTERO, J. y col. Frecuencia de marcadores serológicos del virus B en maternas. Rev Col Gastroent 1988; 3(3): 131.

26. STEVENS, C.E.; BEASLEY, R.P.; TSUI, J. et al. Viral hepatitis in pregnancy. Problems for the clinical dealing with the infant. Pediatr Rev 1980; 2: 121 .

27. STEVENS, C.E.; NEUROTH, R.A.; BEASLEY, R.P. et al. HBeAg and anti $\mathrm{HBe}$ detection by radioinmunoassay: correlation with vertical transmition of hepatitis B in Taiwan. J Med Viral 1979; 3: 237.

28. STEVENS, C.E.; TAYLOR, P.E.; TONG, M.J. et al. Yeast-recombinant hepatitis B vaccine: efficacy with hepatitis B immune globulin in prevention of perinatal hepatitis B transmission. JAMA 1987; 257: 2612-6.

29. SUMMERS. The pregnant hepatitis B carrier; evidence favoring comprehensive antepartum screening. Obstet Gynecol 1987; 69: 701.

30. SYNMAN, Dr. Hepatitis in pregnancy. N Engl J Med 1985; 313: 1398.

31. TONG, M.J. et al. Studies on the maternal-infant transmission of viruses which cause acute hepatitis. Gastroenterology 1981; 80: 999.

32. XU, Z.Y. et al. Prevention of perinatal acquisition of hepatitis B virus carriage using vaccine. Pediatrics 1985; 76: 713-18.

33. ZUCKERMAN, G.R.; HACKER, E.J.; AACH, R.D. Epidemological clinical correlates of hepatitis B antigen subtypes. Gastroenterology 1974; 66: 408. 